\title{
O Investimento Direto Externo Espanhol na América Latina: Determinantes e Impactos
}

\author{
Santos Miguel Ruesga Benito, \\ André Moreira Cunha, \\ Marcos Tadeu C. Lélis e \\ Julimar da Silva Bichara*
}

Resumo: $O$ objetivo desse artigo é analisar as causas e efeitos dos investimentos estrangeiros diretos (IDE) espanhóis na América Latina. Entre o começo dos anos 1990 e 2000, foi notório o movimento de internacionalização das empresas espanholas para o espaço econômico latino-americano; representando cerca de 1/5 dos fluxos de IDE que se direcionaram para a América Latina. Esta proporção foi maior nas economias sul-americanas. Através de uma análise de dados em painel para 11 páses da região no período 1993 - 2003, encontraram-se evidências de que os investimentos espanhóis que se direcionaram para a América Latina foram determinados por uma interação entre os assim-chamados push-factors - no caso, o tamanho da economia espanhola - e os pull-factors (tamanho das economias latino-americanas, abertura comercial e privatizações).

Palavras-chave: Investimento Direto, Espanha, América Latina.

Abstract: The objective of this article is to analyze the causes and effect of the Spanish foreign direct investments (FDI) in Latin America. Between 1990 and 2000, the movement of internationalization of the Spanish companies to the Latin American economic representing around 1/5 of the total FDI flows to Latin America. This ratio was higher in the South American economies. Through an analysis of panel data for 11 countries of the region in the period 1993 - 2003, the evidences show that the Spanish investments had been determined by an interaction enter the push-factors - the size of the Spanish economy - and pull-factors (the size of the Latin American economies, the trade opening and the privatizations).

Keywords: Foreign Direct Investiment, Spain, Latin America.

\footnotetext{
* Santos Miguel Ruesga Benito, Catedrático de Economia Aplicada, Universidad Autónoma de Madrid. E-mail: ruesga@ unam.es. André Moreira Cunha, Professor do Departamento de Economia, Universidade Federal do Rio Grande do Sul. E-mail: amcunha@hotmail.com. Marcos Tadeu C. Lélis, Doutorando do PPGE/UFRGS, Professor da Unisinos. E-mail: mcaputi@uol.com.br. Julimar da Silva Bichara, Professor Titular Interino, Universidad Autónoma de Madrid. E-mail: jsbichara@hotmail.com. Recebido em 01/06/07 e aceito em 02/07/07.
} 


\section{Introdução}

Uma das características centrais do processo de globalização econômica tem sido a ampliação da mobilidade de capitais entre as economias. A literatura recente $^{1}$ tem procurado avaliar os impactos da liberalização financeira sobre as economias receptoras de capitais, com ênfase para a experiência dos países em desenvolvimento. No plano teórico sugere-se que há canais pelos quais a liberalização financeira tenderia a estimular as economias receptoras em termos de um maior crescimento da renda. O canal direto implicaria a ampliação da poupança mobilizável para a realização de investimentos. Assim, a liberalização financeira permitiria o aprofundamento dos mercados financeiros domésticos e, assim, mais investimentos e amortecimento das flutuaçóes nos padróes de consumo. Os canais indiretos seriam aqueles pelos quais a eficiência econômica e a qualidade das instituiçóes poderiam ser aprimorados pela abertura aos capitais forâneos. Isto porque, junto com os recursos financeiros viriam novas tecnologias, capacidade de gestão, e imposiçóes por estabilidade macroeconômica e institucional. Em paralelo aos argumentos teóricos, as evidências empíricas da realização plena destes efeitos positivos ainda não permitem que se chegue a uma conclusão inequívoca sobre os feitos da liberalização financeira sobre os países em desenvolvimento. As avaliaçóes empíricas (PRASAD et al., 2003) não têm gerado resultados suficientemente robustos para que se possa estabelecer uma relação de causalidade entre liberalização financeira e crescimento e/ou estabilidade macroeconômica. Pelo contrário, a experiência das últimas três décadas vão no sentido contrário: a ampliação da absorção de poupança externa, em última instância determinada por ciclos financeiros exógenos às economias receptoras, tem estado associada à instabilidade macroeconômica.

Nestes marcos gerais costuma-se tratar o caso dos investimentos diretos estrangeiros (IDE) como uma modalidade de financiamento mais virtuosa, tanto por seus efeitos diretos, quanto indiretos. É por isso que o presente trabalho se propóe a estudar as causas e efeitos dos investimentos estrangeiros espanhóis na América Latina. Trabalha-se esse recorte - os investimentos espanhóis - pois foi notório o movimento de internacionalização das empresas espanholas para o espaço econômico latino-americano. Entre o começo dos

\footnotetext{
${ }^{1}$ Ver, por exemplo, Rodrik (1998), Cepal (2002a), Prasad et al. (2003), World Bank (2005), OECD (2002), Machinea e Vera (2006).
} 
anos 1990 e 2000, cerca de 1/5 dos fluxos de IDE que se direcionaram para a América Latina se originaram na Espanha. Esta proporção foi maior nas economias sul-americanas ou entre as principais economias latinoamericanas. Tal fato ganha mais relevância quando se considera que houve uma aceleração na entrada de IDE na região, de modo que o estoque de IDE com respeito ao PIB passou de 9\% nos anos 1980 para 32\% no começo do século XXI. Empresas controladas por capitais espanhóis tornaram-se líderes em diversos setores das economias latino-americanas.

Estruturou-se o trabalho da seguinte forma. Inicia-se com uma avaliação sobre as tendências recentes de reformas estruturais, participação do IDE e desempenho macroeconômico na América Latina. Posteriormente analisase a presença dos capitais espanhóis na região e se faz uma breve revisão sobre a literatura que procura avaliar os impactos do IDE sobre as economias receptoras. $\mathrm{Na}$ seqüência faz-se um exercício econométrico para avaliar os determinantes do investimento direto espanhol na América Latina e seus impactos sobre crescimento, investimentos, exportaçóes, produtividade e emprego das economias hospedeiras. Com respeito às causas identificou-se que o movimento de entrada de investimentos espanhóis pode ser explicado pelo tamanho das economias de origem e destino e pelo processo de privatização na região. Este resultado vai ao encontro de parte da literatura, especialmente de estudos setoriais. Por outro lado, não foi possível estabelecer uma relação robusta entre os investimentos espanhóis e o desempenho do lado real das economias latino-americanas. Interpretou-se estes resultados à luz de trabalhos anteriores que sugerem que quando há uma maior concentração do IDE em setores de não-comercializáveis gera-se um impacto tênue sobre variáveis macroeconômicas que avaliem crescimento, exportaçóes, etc. Seguem as consideraçóes finais.

\section{Reformas estruturais, IDE e desempenho macroeconômico na América Latina}

A partir da segunda metade dos anos 1980 e, de forma mais intensa, ao longo dos anos 1990, os países latino-americanos experimentaram um conjunto intenso de reformas econômicas e institucionais. $\mathrm{O}$ modelo de 
desenvolvimento centrado nos mercados internos e com forte participação do Estado, herdado do período nacional desenvolvimentista, deu lugar a um novo arranjo baseado na liberalização comercial e financeira, na desregulamentação dos mercados e nas privatizaçôes. Em geral, o crescimento dos anos 1990 foi superior ao verificado na "década perdida" dos anos $1980^{2}$. As exportaçóes cresceram em termos nominais e os países da região absorveram um volume recorde de investimento estrangeiro. A inflação alta e crônica foi debelada e, no início do século XXI, a situação fiscal da maioria dos países do continente era relativamente mais favorável. Todavia, o período de adaptação à globalização econômica e de reformas pró-mercado náo garantiu o alcance de uma trajetória sustentada e robusta de crescimento com estabilidade macroeconômica. As crises financeiras foram recorrentes, o que comprometeu o desempenho geral das economias.

No plano comercial a intensa abertura veio acompanhada de alteraçóes expressivas nos regimes aduaneiros e proliferação de acordos de comércio (multilaterais, regionais e bilaterais). Machinea e Vera (2006) estimaram que, para o conjunto da região, a tarifa média para o status de nação mais favorecida caiu de cerca de $100 \%$ na década de 1980, para $24 \%$ nos anos 1990 e para menos de $10 \%$ em 2004 . O coeficiente de abertura comercial ${ }^{3}$ teria passado de $7,8 \%$ na média do período $1980-1983$ para 23\% na média 20032005. Entre 1990 e 2004, o volume físico de exportaçôes na América Latina cresceu a uma taxa anual de $8,5 \%$, um ritmo superior ao das seis décadas anteriores e só superado pelas economias asiáticas (MACHINEA, VERA, 2006, p. 8). É bem verdade que tal ritmo foi superior no México e América Central, do que na América do Sul, onde as maiores economias, Argentina e Brasil, tiveram uma performance inferior à média continental (CEPAL, 2004). Apesar disso, os anos 1990 foram marcados pelo predomínio de déficits em conta corrente, dado o forte incremento nas importaçôes de bens e serviços e a ampliação no pagamento de rendas. Os modelos de estabilização baseados na adoção de âncoras cambiais, e as subseqüentes apreciações das

\footnotetext{
${ }^{2}$ A Cepal (2004) estimou em 3,2\% o crescimento médio anual dos anos 1990, contra os 1\% dos anos 1980. Cabe registrar, todavia, que o crescimento no período desenvolvimentista (1950-1980) foi de 5,5\%. Entre 1980 e 2002 a média anual foi de $1,9 \%$. Em termos per capita a diferença entre o boom desenvolvimentista e a estagnação do último quarto de século é ainda mais marcante: $2,7 \%$ contra $0,1 \%$.

${ }^{3} \mathrm{O}$ somatório de exportações e importações como proporção do PIB, a preços constantes de 1995.
} 
moedas domésticas, em um contexto de forte liquidez externa (até 1997) e intensa abertura financeira, implicaram em forte dependência na absorção de poupança externa (WORLD BANK, 2005).

Os principais países da regiáo experimentaram ciclos curtos de euforia com a entrada de investimentos diretos e em portfólio, seguidos de crises financeiras, no que ficou conhecido como processos de "sudden stop", ou como analisado pelo FMI, de dinâmica "feast or famine". As estruturas produtivas e de comércio exterior seguiram fortemente dependentes de setores produtores e processadores de commodities primárias e industriais. Tal fato ganho relevo quando se compara o desempenho das principais economias emergentes da América Latina com os países Asiáticos. Assim, neste item analisaremos as características mais gerais da entrada de capitais estrangeiros nesse novo período de internacionalização. Em uma perspectiva histórica mais ampla é importante lembrar que os investimentos diretos que se enraizaram nos países latino-americanos no período anterior à etapa atual globalização econômica, buscavam, via de regra, contornar as barreiras (tariff jumping) ao comércio consolidadas no imediato pós-guerra. Tais investimentos, ditos "horizontais", visavam atender aos mercados internos em um mundo de forte protecionismo. Nos últimos anos, em função dos processos de redução dos custos de transação no comércio internacional (forte queda nos impostos de importação, barreiras não-tarifárias, custos de transporte, comunicações e outras operaçóes de logística) e de aumento na eficiência dos processos de conexão eletrônica das atividades econômicas, foi possível às empresas transnacionais levarem ao limite seus processos de reestruturação produtiva. As diversas etapas dos processos produtivos foram relocalizadas espacialmente, permitindo a exploração das vantagens locacionais específicas de cada país, em especial: recursos naturais, custos de mão de obra, proximidade dos principais mercados consumidores, estabilidade macroeconômica e institucional, etc. Assim, no ciclo mais recente de boom de IDE os investimentos "verticais" viabilizaram esse padrão de divisão internacional do trabalho intra-grupos, por alguns denominada de redes hierarquizadas de valor. Cérebro (tecnologia, gestão estratégica, finanças, etc.) e corpo (montagem e distribuição dos produtos aos consumidores finais) puderam se separar, ainda mais, em uma economia efetivamente globalizada. Nos investimentos do tipo "horizontal" 
o tamanho dos mercados locais tende a ser a variável mais importante. Esse fator pode ser relativizado com os investimentos "verticais" (MACHINEA, VERA, 2006).

No caso particular dos países da América Latina, os investimento do tipo "vertical", especialmente na indústria, permitiram uma maior vinculação das unidades produtivas locais das empresas transnacionais com suas redes de comércio internacional, o que implicou na solidificação nos vínculos entre comércio (exportações e importações) exterior e investimento direto. Tratase de uma mudança com o padrão anterior de estratégias que enfatizavam o pleno atendimento dos mercados locais protegidos. Por outro lado, no setor de serviços, predominaram estratégias mais próximas o estilo "horizontal", na medida em que o foco na exploração dos mercados locais, sobrepôs-se à lógica de integração em redes globais de comércio intra-grupo. Aqui os vínculos entre comércio exterior e IDE são menos robustos (MACHINEA, VERA, 2006).

As diferenças explicitadas anteriormente entre investimentos "horizontais" e "verticais" são relevantes quando se analisa a experiência espanhola recente de investimentos na América Latina. Isto porque a concentração em setores de "não comercializáveis", como os serviços financeiros e telecomunicaçôes, ou mesmo em setores onde há interfaces de comércio internacional, como em energia (produção e distribuição de energia elétrica e petróleo e gás), sugere a possibilidade de vínculos frágeis entre a maior presença do capital espanhol no continente e o desempenho de alguns agregados macroeconômicos, como as exportaçóes e o resultado em conta corrente do balanço de pagamentos. É importante lembrar que os investimentos localizados no setor de serviços podem gerar uma pressão adicional por divisas (para viabilizar a remessa de lucros, dividendos e outros tipos de rendimentos associados à propriedade de ativos produtivos e financeiros) sem a contra-partida de uma oferta adicional equivalente de moeda conversível. Potencialmente podem ocorrem desequilíbrios de pagamentos internacionais derivados do perfil de internacionalização das economias hospedeiras, a despeito da maior ou menor qualidade de sua gestão macroeconômica e de suas instituiçôes.

Partindo-se da análise dos investimentos na economia mundial, é possível se perceber que no período 1990-1999 os fluxos médios de entradas de 
investimento direto externo (IDE) ${ }^{4}$ atingiram o montante de mais de US\$ 400 bilhóes por ano, um valor quatro vezes superior ao verificado entre 1980 e $1989^{5}$. Tanto em termos absolutos (em dólares correntes), quanto em termos relativos (como proporção do PIB das economias receptoras) verificou-se uma intensa aceleraçáo nos fluxos de IDE nos anos 1990. No final dessa década tais fluxos ultrapassaram a casa de um trilhão de dólares, o equivalente a mais de $4 \%$ do PIB mundial. Desde o início dos anos 1970, os países desenvolvidos vêm concentrando mais de $2 / 3$ dos fluxos recebidos. A década de 1990 foi a que experimentou uma maior participação relativa dos países em desenvolvimento. Ainda assim, é interessante notar que as entradas de IDE como proporção da renda desses dois conjuntos de países apresentam um padrão de comportamento semelhante. Vale dizer, se ao longo das décadas de 1970 e 1980, tanto nas economias avançadas quanto nas regióes periféricas as entradas de IDE oscilaram na ordem de $1 \%$ do PIB. É somente nos anos 1990 que, nos dois grupos de países, tal proporção atinge níveis três ou quatro vezes superiores àquela média histórica.

$\mathrm{O}$ aumento nos fluxos de IDE fez com que o estoque de capital estrangeiro crescesse fortemente ao longo das últimas décadas, em todas as regiōes. Neste sentido o caso latino-americano merece destaque, na medida em que, no período 2000-2004, a América Latina se tornou a região onde o estoque de investimentos diretos apresenta o maior peso relativo quando se compara o porte das economias hospedeiras. Tal proporção, de cerca de $30 \%$ do PIB, é $50 \%$ superior à média internacional de $20 \%$ do PIB. Nas últimas duas décadas (especialmente nos anos 1990) a entrada de IDE nos países asiáticos foi superior, em termos relativos, às entradas verificadas na América Latina (gráfico). Ainda assim, o estoque de investimentos estrangeiros como proporção da renda atingiu valores relativos mais elevados na América Latina no início do século XXI. Tal fato deve estar refletindo o maior ritmo de crescimento das economias asiáticas, de modo que para um mesmo volume de investimento como proporção do PIB, a taxa de crescimento da renda foi maior na Ásia. Lembre-se que nos últimos vinte e cinco anos, enquanto a América Latina vem crescendo abaixo da média mundial (que vem oscilando

\footnotetext{
${ }^{4}$ De agora em diante, salvo explicitação em contrário, todos os dados de IDE referidos são sobre as entradas de capitais.

${ }^{5}$ Estimativas com base nos dados dos World Investment Reports da Unctad (www.unctad.org).
} 
entre $3 \%$ e $4 \%$ ao ano), os países asiáticos vêm se expandindo a taxas médias duas ou três vezes superiores.

\section{Investimento espanhol na América Latina: literatura e evidências}

A literatura ${ }^{6}$ tem destacado que as empresas espanholas tiveram um papel extremamente ativo como fontes de investimento direto externo para os países latino-americanos nos anos 1990. Tais investimentos se concentraram em alguns setores-chave, especialmente em serviços, e foram liderados por poucos grandes grupos. Mais especificamente, no setor de serviços financeiros com os grupos Santander Central Hispano (SCH) e Bilbao Vizcaya Argentaria (BBVA), no setor de telefonia, com o grupo Telefônica de Espanha, e no setor de energia com os grupos Repsol-YPF, Endesa, Iberdrola e Unión Fenosa. O marco inicial desse processo foi a aquisição das empresas nacionais de telefonia da Argentina e Chile, no ano de 1990, ainda que a maior parcela dos investimentos tenha ocorrido na segunda metade da década. Há pelo menos dois conjuntos de determinantes para a onde de aquisiçóes e investimentos espanhóis na América Latina. O primeiro reflete os elementos externos às economias receptoras, mas internos à economia espanhola ("push factors"), bem como as reorientações estratégicas dos principais grupos econômicos do país. Ao longo dos anos 1980 e 1990 a Espanha também experimentou um processo de adaptação a uma ordem internacional marcada pela globalização econômica e pela redefinição do papel do Estado na economia. Ademais, a adesão à União Européia acelerou os desafios de reestruturação institucional e econômica. Os grupos espanhóis vislumbraram no espaço econômico latino-americano a oportunidade de sua internacionalização, dado que, na Europa, a presença de rivais melhor posicionados, como os grupos alemães, italianos e franceses, limitaria seu potencial de crescimento.

Paralelamente os países latino-americanos realizavam programas de privatização e desregulamentação de suas economias, criando ativos vendáveis em diversos setores econômicos previamente dominados por empresas estatais ou por empresas privadas nacionais de menor porte relativo que suas

\footnotetext{
${ }^{6}$ Dos vários trabalhos que vêm analisando os investimentos espanhóis na América Latina, destacamos Cepal (2002a, 2006), Sánchez Díez (2002), Ruesga e Bichara (2004), Casilda Béjar e Calderón (2000), Casilda Béjar (2003), Chislett (2003) e Ruesga e Bichara (2004).
} 
congêneres nos países avançados. Junte-se a isso a finalização dos processos de renegociação da dívida externa e a consolidação da estabilidade monetária, após anos (ou décadas) de descontrole inflacionário. A liberalização comercial e financeira e as reformas nos marcos legais que antes caracterizavam o modelo de "substituição de importaçóes" representaram a conformação de um ambiente de negócios mais atraente aos investidores estrangeiros. Assim, esse segundo conjunto de elementos representaria os chamados "pull factors" na determinação dos fluxos de investimento.

Menos analisado tem sido a participação recente do capital espanhol nos países latino-americanos, nos marcos de um ciclo de crescimento liderado pelas exportaçôes de commodities (que se inaugura em 2003) e após a digestão das crises financeiras que marcaram o final dos anos 1990 e o começo do século XXI. Neste novo momento os investimentos espanhóis perderam espaço relativo. Ademais as empresas estatais e privadas nacionais, localizadas nos setores produtivos mais estimulados pelo novo boom, parecem estar retomando um papel de maior relevo no quadro produtivo e comercial regional. Não se pode desconhecer que os setores econômicos privilegiados pelos investimentos espanhóis - serviços bancários, telefonia e energia - com exceção do segmento de petróleo e gás, não estão na linha de frente do novo ciclo de crescimento dos países latinos inaugurado em 2003. Assim, de acordo com a Cepal (2006, p. 7) no período 1996-2000, os EUA responderam por cerca de $35 \%$ do IDE (fluxos de entrada), seguido da Espanha, com uma proporção de 23\%. Já entre 2001-2005 os EUA consolidaram sua posição com quase $40 \%$ do IDE. A Espanha recuou sua participação para $6 \%$, proporção inferior aos $12 \%$ do segundo principal investidor, a Holanda (CEPAL, 2006, p. 7).

$\mathrm{Na}$ mesma linha, o tradicional informe anual da Cepal "La Inversión Estranjera em América Latina y Caribe” traz um mapeamento do desempenho das 500 maiores empresas não-financeiras em atuação no continente e das 200 maiores empresas exportadoras. Na sua edição mais recente (Cepal, 2006) verifica-se que, para dados do ano de 2004, as 500 maiores empresas apresentaram um faturamento equivalente a $46 \%$ do PIB da região, ao passo que as 200 maiores exportadoras responderam por $58 \%$ do total exportado pelos países da região. Nos dois casos temos importante amostra 
do tecido empresarial que conforma a estrutura econômica latino-americana, representado pelos maiores grupos empresariais - estatais, privados nacionais e estrangeiros. A Cepal (2006) sugere uma mudança no "mapa empresarial" na América Latina, quando se compara o período de liberalização e boom de entrada de investimentos estrangeiros, na década de 1990, com o novo ciclo de crescimento do início do século XXI. Se, ao longo dos anos 1990, a participação das transnacionais no total das vendas das 500 maiores cresceu de cerca de $30 \%$ para mais de $35 \%$ e, nas exportaçôes das 200 maiores exportadoras, de cerca de $25 \%$ para quase $40 \%$, entre 2000-2004 as empresas privadas locais e as estatais ampliaram sua participação no faturamento e exportaçóes. Em 2004 as privadas locais atingiram 47\%, as estatais 24\% e as transnacionais $29 \%$ do faturamento - o que revela uma queda expressiva frente ao auge experimentado na segunda metade dos anos 1990, quando as estrangeiras chegaram a participar com 40\%, em 1999, e 36\%, em 2000. Quanto às exportaçóes a queda da participação das estrangeiras foi ainda mais pronunciada, bem como intenso foi o incremento na participação relativa das empresas estatais. A Cepal aponta que a estagnação das vendas das filiais de empresas estrangeiras localizadas no México seria a principal causa daquela queda relativa, ao passo que o boom das commodities explicaria a estabilidade da participação das estatais e o crescimento das privadas locais.

O desempenho das 500 maiores em 2004 refletiu a recuperação da economia mundial. Pela primeira vez o faturamento total excedeu a casa de um trilhão de dólares (mais especificamente, US\$ 1,1 trilhão). Houve um crescimento de $29 \%$ sobre o ano de 2003, depois da estagnação no período 2000-2002. É importante notar que três países - Argentina, Brasil e México - concentraram cerca de $85 \%$ das vendas das empresas transnacionais em operação na América Latina. Não à toa essas mesmas três economias vêm respondendo por mais de $2 / 3$ da renda total da regiâo. Em 2004 um pouco mais de $50 \%$ do estoque de investimento direto externo e mais de 60\% do somatório dos fluxos de entrada de IDE entre 1990 e 2004 estavam concentrados nas três grandes economias do continente ${ }^{7}$. Em 2004, as exportações das 200 maiores atingiram a marca de US\$ 256 bilhões. As maiores empresas exportadoras foram as estatais petroleiras, as

\footnotetext{
${ }^{7}$ Estimativas dos autores com base nos dados dos Anexos Estatísticos da Unctad (2005a).
} 
filiais de empresas transnacionais localizadas no México, especialmente as norte-americanas GM, Delphi, HP, Lear e GE, e as alemãs Daimler-Chrysler e Volskswagen, e a filial brasileira das empresas norte-americanas Cargill e Bunge.

Tome-se agora o conjunto das 50 maiores empresas transnacionais nãofinanceiras em operação na América Latina. Em 2004 esse universo faturou US\$ 259 bilhóes - 12\% acima do montante de 2003. As empresas dos EUA responderam por $45 \%$ daquele faturamento, seguidas das empresasespanholas, com 14\%. A participação espanhola cresceu dois pontos percentuais frente aos dados de 2003 (ainda que siga bem abaixo do auge verificado no final dos anos 1990) em função de dois fatores fundamentais: (i) a aquisição, por parte do grupo Telefônica de Espanha, das operaçóes da BellSouth no continente; e (ii) o aumento das vendas dos grupos Endesa e Iberdola, com este último entrando no mercado mexicano no ano de 2004. Ainda em 2004, o setor financeiro seguiu sob a liderança dos espanhóis Santander Central Hispano (SCH) e Bilbao Vizcaya Argentaria (BBVA) e do norte-americano Citicorp. $\mathrm{O}$ período de recuperação da economia latino-americana fez com que os 250 maiores bancos no continente experimentassem uma expansão de seus ativos em 30\% e dos lucros em 69\% sobre os dados de 2003, (CEPAL, 2006). Conforme destacado anteriormente, e tomando por base os dados da UNCTAD (2005a), é possível se perceber que Argentina, Brasil e México responderam por mais de $60 \%$ dos fluxos de entrada de IDE no período 1991-2004. Nestes países a Espanha se tornou um importante investidor no ciclo de privatizaçóes dos anos 1990. Assim, de acordo com estimativas da Cepal (2006) para os fluxos acumulados entre 1996 e 2005, a participação espanhola foi de $14 \%$ no Brasil, $10 \%$ no México e $44 \%$ na Argentina. No Chile tal participação foi de $30 \%$, na Colômbia de $18 \%$ e na Venezuela de $8 \%$.

O período 1992-2000 concentrou a maior parte dos investimentos europeus na América Latina, o que coincidiu com a fase inicial de liberalização econômica e reformas estruturais no continente. A Cepal (2002b) estimou em US\$ 144 bilhóes os fluxos de IDE europeus acumulados naquele período, dos quais a metade (US\$ 72 bilhóes) se originou na Espanha. Este país concentrou seus investimentos através dos grupos Telefônica de Espanha, 
Santander Central Hispano (SCH), Bilbao Vizcaya Argentaria (BBVA), Repsol-YPF, Endesa, Iberdrola e Unión Fenosa. Note-se que, enquanto entre 1990 e 1994 a Grã-Bretanha liderou os investimentos europeus na América Latina, com 40\% do total, seguido da Espanha com 16\%, no período 19952000 a Espanha tomou a dianteira com 44\% dos investimentos contra os $13 \%$ da Grã-Bretanha.

\section{Efeitos macroeconômicos do Investimento Direto Externo na América Latina}

Desde o nascimento da economia política, especialmente nos trabalhos de Adam Smith e David Ricardo, a literatura econômica ${ }^{8}$ vem destacando que as situaçóes de livre comércio seriam superiores às de autarquia. No plano do comércio exterior isso implicaria na existência de uma associação positiva entre o grau de abertura comercial ${ }^{9}$ e o crescimento econômico, o que justificaria a defesa de políticas de liberalização comercial. A partir do final dos anos 1980 as políticas de reforma estrutural nos países em desenvolvimento, especialmente na América Latina, foram inspiradas, dentre outras coisas, por esse tipo de perspectiva teórica, aliada à interpretação sobre os determinantes do sucesso do modelo de desenvolvimento dos países asiáticos (WORLD BANK, 1993). Tais políticas, consagradas no assim-chamado "Consenso de Washington", foram amplamente adotadas pelos países em desenvolvimento (RODRIK, 2005). Todavia, com resultados que não traduziram o otimismo original de seus defensores, as políticas liberalizantes vêm sendo questionadas como capazes de per se garantir trajetórias sustentáveis de desenvolvimento (WORLD BANK, 2005). Não à toa autores influentes vêm questionando a "consenso" do mainstream da economia acerca dos efeitos dos processos de liberalização comercial (RODRIGUEZ, RODRIK, 2000; WINTERS, 2004). Não se nega que a integração à economia internacional seja uma situação superior ao "fechamento". Por outro lado, enfatiza-se que há mais de um tipo legítimo de regime de comércio ou de políticas (ou estratégias) de integração capazes de potencializar os benefícios potencialmente gerados

\footnotetext{
${ }^{8}$ Rodriguez e Rodrik (2000) e Winter (2004) fazem uma ampla revisão da literatura.

${ }^{9}$ Capturado por indicadores como exportações/PIB ou exportações mais importações sobre o PIB. É bastante comum a associação entre o crescimento das exportações e a expansão da renda.
} 
pelo acesso a mercados ampliados e fontes alternativas de tecnologia e outros ativos produtivos.

Esse tipo de questionamento se amplia quando há a inclusão dos fluxos financeiros (BHAGWATI, 1998). A literatura convencional ${ }^{10}$ sugere que a abertura financeira traz benefícios diretos e indiretos para receptores e fornecedores de capital. Estes últimos podem ampliar seu retorno (ajustado pelo risco) e diversificar as carteiras de investimento ao direcionar seus recursos para os países em desenvolvimento. Seria natural esperar um retorno médio dos investimentos superior nos países onde há escassez relativa de capital - por isso mesmo seriam "em desenvolvimento" ou "emergentes" do que nos países avançados, onde aquele é mais abundante. Na perspectiva dos tomadores de recursos haveria benefícios diretos com a "integração financeira" pois o acesso à poupança externa permitiria o aprofundamento dos mercados financeiros domésticos e, com isso, a viabilização de investimentos produtivos. Com estes seria possível assegurar níveis mais elevados de crescimento econômico. Além do capital, os investimentos estrangeiros costumam ampliar o acesso das economias hospedeiras a novas tecnologias e capacidades gerenciais. Ademais os países interessados em captar poupança externa deveriam perseguir políticas macroeconômicas e arranjos institucionais capazes de transmitir segurança aos investidores estrangeiros, o que, nos termos dessa perspectiva teórica, contribuiria para a estabilidade econômica e política. Estes seriam os benefícios indiretos da liberalização financeira ${ }^{11}$.

Assim, tanto na dimensão comercial, quanto na financeira, não parece haver consensos robustos quanto aos efeitos das estratégias de liberalização econômica sobre as economias em desenvolvimento. Há especificidades institucionais no modo como os países formulam suas estratégias de integração, bem como especificidades históricas (econômicas e geopolíticas)

\footnotetext{
${ }^{10}$ Ver Rodrik (1998), Prasad et al. (2003) e World Bank (2005).

${ }^{11} \mathrm{O}$ trabalho de Prasad et al. (2003) diferencia "liberalização financeira" (ou abertura da conta capital) de "integração financeira". O primeiro termo se refere a aspectos normativos capazes de garantir a livre mobilidade de capitais, vale dizer a aquisição de ativos financeiros e de dívida no exterior por parte de residentes, bem como a aquisição de ativos financeiros e contratação de dívida nos mercados locais por parte de não residentes. Já a integração financeira traduziria o movimento efetivo de capitais. Assim, um país poderia ter uma legislação liberalizante sem atrair poupança externa, como no caso de muitos países africanos, ou, no extremo oposto, uma legislação mais restritiva, porém atraindo grandes volumes de capitais, como no caso da China.
} 
que condicionam o ambiente internacional quando dos períodos de maior ou menor interação entre as economias locais e a economia mundial.

Os estudos específicos ${ }^{12}$ sobre os determinantes e os efeitos da liberalização econômica dos países latino-americanos no período de reformas estruturais domésticas e de globalização no plano externo - ou seja, a partir do final dos anos 1980 e início dos anos 1990 - têm sugerido que: (i) as exportaçóes cresceram relativamente mais entre os países que mais avançaram em suas estratégias liberalizantes; (ii) os investimentos diretos estrangeiros parecem estar positivamente associados ao aumento das exportaçóes e à aceleração do crescimento econômico ${ }^{13}$; (ii) ainda assim, os países da região, com exceção do Chile, não lograram atingir uma trajetória sustentável e robusta de crescimento econômico; (iv) houve intensa instabilidade financeira e recorrentes crises bancárias, cambiais e "gêmeas". Tais fatos estilizados sugerem que se interpretar com cautela e de forma a respeitar as experiências individuais dos países latino-americanos as evidências acerca dos efeitos da maior participação do capital estrangeiro na região, mesmo quando se enfatiza a modalidade de investimento direto estrangeiro.

A literatura especializada ${ }^{14}$ sugere o IDE pode afetar de forma positiva o crescimento econômico. Além de ser uma fonte relativamente mais estável de financiamento externo, o investimento direto aporta novas tecnologias, capacidades gerenciais e canais de acesso a mercados externos (finais, para os bens de consumo, e de insumos). $\mathrm{Na}$ modalidade greenfield investment o IDE significa novas unidades produtivas sendo instaladas, o que criaria empregos e renda adicionais nas economias hospedeiras. Adicionalmente, quanto mais integradas as unidades das empresas transnacionais com o tecido produtivo previamente existente nos países hospedeiros, maiores seriam

\footnotetext{
${ }^{12}$ Há uma vasta literatura teórica e empírica sobre esse tema. Sugerimos aqui balanços recentes que organizam o debate e fornecem evidências atualizadas, tais como Cepal (2002a, 2004, 2006), Unctad (2004, 2005b), Machiena e Vera (2006) e World Bank (2005).

${ }^{13}$ Trata-se aqui da comparação entre os anos 1990 com a "década perdida" dos 1980. Já a comparação com o período desenvolvimentista (entre as décadas de 1950 e 1970) ou a comparação da performance latino-americana com a asiática, revelam que a trajetória dos países região, com exceção do caso chileno, foi decepcionante (CEPAL, 2004; WORLD BANK, 2005).

${ }^{14}$ Os World Investment Reports publicados anualmente para Unctad (www.unctad.org) são uma referência obrigatória para os interessados na atualização das evidências empíricas e evolução das percepções teóricas e de política econômica acerca da questão dos investimentos externos e estratégias de empresas transnacionais. Uma revisão atualizada da literatura está disponível em OECD (2002) e Machinea e Vera (2006).
} 
os efeitos de transbordamento (spill-over effects). A própria concorrência entre empresas transnacionais e locais poderia estimular essas últimas a acelerar seus processos de capacitaçáo tecno-produtiva, na medida em que houver uma elevação dos padróes de qualidade nos produtos e processos introduzidos pelas transnacionais. A intensidade daqueles efeitos dependerá fortemente das características específicas do investimento estrangeiro - se horizontal ou vertical - e da natureza dos setores econômicos ${ }^{15}$ envolvidos na absorção dos investimentos (seu grau de complexidade e encadeamento com outras atividades econômicas). Assim, a formação de enclaves de empresas transnacionais em setores que estabelecem poucos encadeamentos para trás e para frente - por exemplo, o processamento de recursos naturais visando os mercados externos - pode gerar efeitos líquidos negativos para o conjunto da economia (MACHINEA, VERA, 2006).

Ao longo das últimas décadas, os investimentos diretos vêm apresentando uma contribuição crescente no montante total de investimentos das economias hospedeiras. Tal proporção é particularmente maior nos países latino-americanos. Todavia, em linha com a tradicional argumentação de Feldstein e Horioka (1980), essa modalidade de poupança externa pode ter uma contribuição marginal no total dos investimentos domésticos realizados. É importante lembrar que estudos empíricos ${ }^{16}$ de análise transversal vêm encontrando relaçóes positivas condicionais entre IDE e crescimento, onde o primeiro tenderia a estimular o segundo a partir do momento em que os países hospedeiros são capazes de preencher alguns requisitos prévios, tais como: um nível mínimo de renda por habitante, um certo padrão prévio de desenvolvimento humano, especialmente em educação, um maior grau de abertura comercial e de profundidade dos mercados financeiros.

Em uma outra dimensão, os efeitos potenciais do investimento direto exterior sobre o comércio internacional não podem ser assumidos como óbvios a priori. Investimentos do tipo "horizontal", que enfatizam o atendimento dos mercados locais, quer no padrão de industrialização por substituiçóes de importaçóes que vigorou entre os anos 1950 e 1970, quer na

\footnotetext{
${ }^{15}$ Alfaro (2003) encontrou evidências de que os IDE no setor primário tem um efeito negativo sobre o crescimento. $\mathrm{Na}$ indústria ele teria um impacto positivo e no setor de serviços o resultado seria ambíguo. A autora fez uma análise crosssection no período 1981-1999 em uma amostra de 47 países.

${ }^{16}$ OECD, Hansen e Rand (2004) e Machinea e Vera (2006) revisam a literatura pertinente.
} 
localização dos investimentos nos setores de "não comercializáveis, como nos anos 1990, tendem a ter poucos vínculos diretos com o comércio exterior. No caso da "substituição de importações" o IDE poderá estar substituindo as importações prévias sem, obrigatoriamente, implicar em uma especialização exportadora. Tal padrão tenderia a reduzir o grau de abertura comercial. Por outro lado, o IDE "vertical", que vincula de forma mais estreita os países hospedeiros com redes internacionais de produção, está mais associado a uma ampliação do comércio exterior (MACHINEA, VERA, 2006).

Neste sentido, um estudo recente da OCDE (OECD, 2002) encontrou vínculos positivos entre IDE e comércio exterior ${ }^{17}$ para as economias avançadas sem, contudo, estabelecer uma evidência robusta de causalidade. No plano teórico seria de se esperar a causalidade no sentido do IDE para o comércio exterior, na medida em que os países hospedeiros tenderiam a se apropriar das facilidades de pertencer a redes de produção previamente internacionalizadas, reduzindo os custos de acesso aos mercados externos. Um esforço mais amplo foi realizado por Aizenman \& Noy (2005), que fizeram uma análise de dados de painel para 83 países entre os anos 1982 e 1993. Os autores separaram dois grupos de países - desenvolvidos e em desenvolvimento - com o intuito de verificar eventuais especificidades associadas ao grau de desenvolvimento dos países e o tipo de investimento direto, se horizontal ou vertical. Para os países em desenvolvimento foi possível encontrar um resultado inicial aparentemente contra-intuitivo, qual seja: os fluxos de comércio no passado afetariam positivamente os investimentos no presente. Já entre os países desenvolvidos não foi possível estabelecer esse mesmo padrão de relacionamento entre aquelas duas variáveis. Adicionalmente, esse mesmo trabalho encontrou uma relação positiva e significativa entre o IDE realizado no passado e comércio exterior no presente para os dois grupos de países. Essa segunda relação foi mais robusta que a primeira.

Dada esta breve revisão de evidências e relaçóes teóricas esperadas, realizamos no próximo item vários exercícios econométricos voltados a encontrar evidências sobre determinantes e efeitos do investimento direto espanhol nas economias latino-americanas.

\footnotetext{
${ }^{17} \mathrm{~A}$ proxy utilizada foi o coeficiente de abertura comercial (exportações mais importações dividido pelo PIB) na média do período 1995-2000. Para o IDE foi utilizada uma média dos fluxos de entradas e saídas naquele mesmo período.
} 


\section{Determinantes do IDE espanhol e seus impactos macroeconômicos na América Latina}

A presente seção busca avaliar os condicionantes macroeconômicos do investimento estrangeiro direto espanhol (IDEs) em direção a América Latina entre os anos de 1993 e 2003. Ademais demarca-se a relação deste agregado com as seguintes variáveis macroeconômicas: taxa de investimento, exportações, produtividade e taxa de desemprego. Para isso, dipóe-se de uma amostra de 11 países ${ }^{18}$ delimitadas no período já citado.

Tem-se, portanto, a mesma unidade de corte transversal (no caso, países) acompanhada em vários anos (1993 a 2003), ou seja, qualificam-se dados combinados, observaçóes repetidas para o mesmo conjunto de unidades seccionais. Essa particularização propicia a utilização de modelos estatísticos estruturados sobre as hipóteses de dados em painel. Estes tipos de modelos oferecem um número de vantagens quando comparados com modelos de cross-section puro ou série de tempo, destacando-se o benefício de que o número de observaçóes é muito maior em modelos estatísticos de dados em painel (BALESTRA, 1992, p. 22). Para o caso do estudo desenvolvido a vantagem torna-se presente, uma vez que se trabalha com onze países, os quais são o corte do modelo (cross-section), observados durante onze anos, indicando um total de 121 observaçóes.

De maneira geral, pode-se delimitar um modelo de dados em painel da seguinte maneira:

$y_{i t}=\beta^{k} \cdot x_{i t}{ }^{k}+\varepsilon_{i t}$

sendo,

$y_{i t}=\mathrm{o}$ valor da variável dependente para a unidade seccional i no tempo $\mathrm{t}$

$x_{i t}=\mathrm{o}$ valor da k-ésima variável explicativa para a unidade seccional $i$ no tempo t

$\varepsilon_{i t}=\mathrm{o}$ valor do resíduo para unidade seccional $i$ no tempo $t$.

Todavia, o resíduo, para o caso de dados em painel, é explicitado como segue:

$\varepsilon_{i t}=\alpha_{i}+v_{i t}$

Onde, $\alpha_{i}$ denota um efeito individual não observado e $v_{i t}$ representa $o$ 18 Argentina, Bolívia, Brasil, Chile, Colômbia, Equador, México, Paraguai, Peru, Uruguai e Venezuela. 
outro termo não observado do resíduo. Apesar de se definir $\alpha_{i}$ como um componente do resíduo individual, isto é, pertinente para cada país e fixo ao longo do tempo, pode-se individualizar esse componente como um termo do intercepto. Assim, ao escolher como modelar o intercepto tem-se a possibilidade de optar por: i) intercepto comum (um mesmo valor para todos os cross-section), ii) intercepto com efeito fixo (valores diferentes para cada cross-section), e iii) intercepto com efeito aleatório (da mesma forma do intercepto com efeito fixo, valores diferentes para cada cross-section ). É na escolha de como definir o intercepto que se residi as principais hipótese sobre o termo $\alpha_{i}$ e sua interaçáo com as variáveis explicativas $\left(x_{i t}{ }^{k}\right)$ do modelo proposto.

A preferência de se trabalhar com intercepto comum leva à hipótese de que não existem individualidades entre as unidades seccionais. Isto é, o investidor espanhol não observa diferença entre os países da América Latina ao definir o destino das suas inversóes, o bloco latino-americano seria o mais importante. As opçôes interceptos com efeitos fixo ou aleatório levam a definição de diferença de comportamento do IDEs para as unidades transversais. Entrementes, tem-se a alternativa de modelar o termo não observado, $\alpha_{i}$, via efeito fixo ou efeito aleatório. A consideração que se faz na especificação de efeito fixo é de que $\alpha_{i}$ é correlacionado com alguma variável explicativa do modelo proposto, ou seja, $\operatorname{cov}\left(\alpha_{i}, x_{i t}{ }^{k}\right) \neq 0$. Já para a situação estruturada sob a hipótese de efeito aleatório não se espera uma correlação entre $\alpha_{i}$ e uma das variáveis explicativas, $\operatorname{cov}\left(\alpha_{i}, x_{i t}{ }^{k}\right)=0$.

Alguns exercícios que se utilizam da estrutura estatística de dados em painel apresentam, em geral, os resultados empregando-se tanto modelos de efeito fixos quanto modelos de efeito aleatório. Segundo Arellano e Bover (1990, p. 9) este tipo de especificação caracteriza-se como um mal entendido, fruto, basicamente, das primeiras aplicaçôes de dados em painel. A escolha de se trabalhar com efeito fixo já pré-supôe uma relação entre $\alpha_{i}$ e as variáveis explicativas oposta a opção de efeito variável, onde, esta definição parte de conjecturas econômicas ou estatística sobre o comportamento da variável explicada do modelo, levando em consideração um termo não observável ${ }^{19}$.

19 Pode-se delimitar a alternativa entre efeito fixo e aleatório em modelos de dados em painel partindo-se do teste estatístico de Hausman, porém, o resultado encontrado é simplesmente um indicador, não se caracterizando como definitivo (JOHNSTON, DINARDO, 1997, p. 458). 
Apresentado alguns pontos com respeito aos fundamentos teóricos dos modelos estatísticos de dados em painel, descreve-se as variáveis que serão empregadas no exercício de determinação do IDEs.

(A) Investimento estrangeiro direto espanhol (IDEs) - utilizou-se esta variável em dólares estadunidenses (US\$) a preços de 2000. Como os dados originais estão denominados em dólares, foi utilizado o deflator da formação bruta de capital, subitem máquinas e equipamentos, da economia estadunidense. Além disso, aplicou-se uma transformação logarítmica nos dados originais. A fonte de dados brutos do IDEs foi Ministerio de Industria, Turismo y Comercio - Secretaria de Estado de Turismo y Comercio - Registro de Inversiones Exteriores e International Financial Statistic Database - FMI.

(B) Renda dos países da América Latina ( $\left.\mathrm{Y}^{\mathrm{al}}\right)$ - caracteriza-se esta variável em US\$ a preços de 2000. A Yal, teoricamente, influencia o IDEs de maneira positiva, vale dizer: espera-se que quanto maior o tamanho da economia do país receptor (ou hospedeiro) maior será o fluxo de investimentos estrangeiros absorvidos. Fez-se uma transformação logarítmica neste indicador. Este agregado apresentou como fonte de dados brutos o World Development Indicators 2005 - Banco Mundial.

(C) Grau de abertura dos países da América Latina (CC $\left.{ }^{a}\right)$ - o grau de abertura é obtido ao se dividir a soma da exportaçôes e importações de mercadorias e serviços não fatores pelo valor do produto interno bruto (PIB). Dessa forma, esta variável encontra-se em índice. Espera-se que quanto maior o $\mathrm{CC}^{\mathrm{al}}$ maior será o fluxo de investimento espanhol. Os dados brutos foram coletados a partir do World Development Indicators 2005.

(D) Inflação média dos últimos cinco anos dos países da América Latina ( In $\left.^{\text {al }}\right)$ - a inflação, no caso desse trabalho, é a variação dos preços ao consumidor em unidades percentuais, sendo caracterizada como uma proxy do nível de estabilidade do país. Isto é, quanto maior este indicador, maior a incerteza econômica da regiáo, diminuindo o potencial de absorção de inversōes estrangeiras. Ao se empregar a média dos últimos cinco anos tem-se o objetivo de uma observação de mais longo prazo. Ademais, esta média foi construída partindo-se de uma média aritmética simples, pois, não se acredita que os agentes econômicos, no momento da decisão de investimento, trabalhem com médias geométricas. Como fonte de dados brutos para o INal tem-se World Development Indicators 2005. 
(E) Renda da Espanha $\left(\mathbf{Y}^{\mathrm{e}}\right)$ - este agregado encontra-se em US\$ a preços de 2000. Teoricamente a relação entre Ye e o IDEs é positiva, ou seja, quanto maior o tamanho da economia de origem dos investimentos maior será este fluxo, sendo que, apresenta-se este agregado em logaritmo. A fonte de dados para a renda espanhola foi World Development Indicators 2005.

(F) Taxa de absorção interna dos países da América Latina (AB $\left.{ }^{\text {al }}\right)$ - sabendo que a absorção interna é simplesmente a soma do consumo total e do investimento de cada país, o $\mathrm{AB}^{\mathrm{al}}$ indica o nível de atividade econômica interno de cada região, sendo construído a partir de valores em US\$ de 2000. Trabalha-se com o número índice da taxa de variação não com o seu valor percentual. Nota-se que o $\mathrm{AB}^{\text {al }}$ caracteriza-se como uma variável diferente do tamanho da economia da região. Espera-se que seu efeito sobre o IDEs seja positivo ${ }^{20}$. A fonte dos dados brutos é o World Development Indicators 2005.

(G) Taxa de absorçáo interna da Espanha $\left(\mathbf{A B}^{\mathrm{e}}\right)$ - as observaçóes assinalada para $\mathrm{AB}^{\mathrm{al}}$ continuam valendo para a $\mathrm{AB}^{\mathrm{e}}$, porém, agora especifica-se o país de origem do investimento.

Definidas as variáveis utilizadas, suas respectivas fontes e os sinais esperados, tem-se a seguinte equação a ser estimada:

$$
I D E s_{t}=\beta_{0}+\beta_{1} Y_{i t}^{a l}+\beta_{2} Y_{i t}^{e}+\beta_{3} A B_{i t}^{a l}+\beta_{4} A B_{i t}{ }^{e}+\beta 5 C C_{i t}^{a l}+\beta_{6} I N_{i t}^{a l}+\varepsilon_{t}
$$

É importante salientar que na equação (3) o termo de intercepto é definido como um único para todos os países $\left(\beta_{0}\right)$. Com efeito, neste primeiro momento, imagina-se que não há diferença de comportamento dos fluxos de investimentos direto espanhóis entre os países da América Latina.

A Tabela 1 apresenta uma primeira aproximação para os determinantes do IDEs voltado para a América Latina. Constata-se que as únicas variáveis estatisticamente não significativa, quando se considera um nível de significância de $5 \%$, são a $\mathrm{AB}^{\mathrm{e}}$ e a $\mathrm{IN}^{\mathrm{al}}$. Com relação ao parâmetro associado a variável que representa o grau de abertura das economias latino-americanas, este apresentou um sinal não esperado, isto é, uma maior abertura comercial menor o fluxo de entradas de investimento direto espanhol. Ademais, AIC

20 Os efeitos das exportações sobre o nível de atividade econômica podem ser captados pela dinâmica do multiplicador dos gastos autônomos. Além do que, a variável CC ${ }^{a l}$ captura as relações econômicas externas de cada país. 
representa o critério de informação de Akaike e CSC indica o critério de Schwarz, a estatística Durbin-Watson (DW) indicou autocorrelação serial nos resíduos.

Tabela 1 - Resultados estatísticos da expressão (3) - Intercepto comum (OLS)

\begin{tabular}{|l|c|c|c|}
\hline \multicolumn{1}{|c|}{ VARIÁVEL } & $\boldsymbol{\beta}_{\boldsymbol{k}}$ & Desvio-padráo & p-valor \\
\hline constante & $-71,41$ & 17,45 & 0.000 \\
\hline$Y^{\text {al }}$ & 1,275 & 0,131 & 0.000 \\
\hline$Y^{\mathrm{e}}$ & 11,778 & 3,099 & 0.000 \\
\hline $\mathrm{AB}^{\mathrm{al}}$ & 10,953 & 2,822 & 0.000 \\
\hline $\mathrm{AB}^{\mathrm{e}}$ & $-0,806$ & 9,303 & 0.931 \\
\hline $\mathrm{CC}^{\text {al }}$ & $-0,834$ & 0,423 & 0.051 \\
\hline $\mathrm{IN}^{\text {al }}$ & $-0,025$ & 0,022 & 0.264 \\
\hline
\end{tabular}

$R^{2}: 0,6458$

AIC: 2,3385

CSC: 2,5003

Antes de buscar qualquer correção no modelo representado pela equação 3 deve-se testar se o comportamento do IDEs caracterizado de forma diferente para cada unidade seccional e entre os anos. Para isso, incluíram-se, primeiramente, variáveis dummies especificadas para cada país e, logo depois, para cada ano, testando, em seguida, a sua significância estatística conjunta. $\mathrm{O}$ resultado do teste em conjunto é exposto na Tabela 2.

Tabela 2 - Teste de significância em conjunto para as dummies por país e nos anos

\begin{tabular}{|l|c|c|}
\hline \multicolumn{1}{|c|}{ Estimador } & Estatística-F & p-valor \\
\hline Intercepto comum (OLS) - dummies países & 3,13 & $\mathbf{0 , 0 0 1}$ \\
\hline Intercepto efeito fixo - dummies anos & 3,09 & $\mathbf{0 , 0 0 2}$ \\
\hline
\end{tabular}

O resultado da estatística-F indica a rejeição da hipótese nula, neste caso não se rejeita a significância conjunta das dummies por país para o estimador com intercepto comum, isto é, estas em conjunto são diferentes de zero. Portanto, pode-se afirmar que, estatisticamente, existem diferenças no comportamento do IDEs entre os países. A conseqüência desse resultado é a necessidade de estimar o intercepto da equação 3 com valores diferentes para cada cross-section. Como já apresentado anteriormente, é importante definir 
a relação entre o componente não observável $\alpha_{i}$ e as variáveis explicativas do modelo já formulado para o IDEs. Tem-se como hipótese que existe uma correlação entre $\alpha_{i}$ (indicado como, por exemplo, institucionalidade dos países da região) e $\mathrm{AB}^{\mathrm{al}}$, ou $\mathrm{IN}^{\mathrm{a}}$, ou, então a própria $\mathrm{Y}^{\mathrm{a}}$, logo, emprega-se estimadores de efeito fixo ${ }^{21}$.

Com respeito à significância conjunta das dummies anuais, rejeita-se a hipótese de que estas em conjunto são diferentes de zero, com um nível de significância de 5\%. Isto é, constata-se que, estatisticamente, existem alterações no comportamento do IDEs entre os anos. Motivado por este resultado inclui-se uma variável binária que representará os anos em que os fluxos de investimento voltado para as privatizaçôes tiveram um valor expressivo. $\mathrm{O}$ corte para caracterizar esta expressividade é dado no momento em que este agregado representa mais que $10 \%$ do movimento total do investimento estrangeiro de cada país. Com efeito, assinalam-se variáveis dummies individualizadas para cada região. Ademais, a fonte de dados utilizada para os valores anuais de privatização dos países da América Latina foi o relatório Privatization Toolkits - Private Sector Development - The World Bank Group.

Dessa forma, a nova estrutura é representada na expressão 4, onde DUal indica a variável binária para os anos de forte entrada de inversóes espanholas direcionadas para privatizaçóes.

$$
I D E s_{i t}=\beta_{0 i}+\beta_{1} Y_{i t}^{a l}+\beta_{2} Y_{t}^{e}+\beta_{3} A B_{i t}^{a l}+\beta_{4} A B_{t}^{e}+\beta 5 C C_{i t}^{a l}+\beta_{\sigma} I N_{i t}^{a l}+\varepsilon_{t}
$$

Ao testar a presença de heterocedasticidade nos resíduos do modelo estatístico representado pela expressão 4, rejeita-se a hipótese de igualdade entre estes, a um nível de significância de 5\% para três especificaçóes propostas (Tabela 3).

\footnotetext{
${ }^{21}$ Acredita-se que existe diferença na institucionalidade de cada país, no entanto, ao longo do tempo as mudanças institucionais ocorreriam de maneira bastante suave. Ademais, dado este resultado, todos os próximos exercícios estatísticos empregaram o estimador de efeito fixo.
} 
Tabela 3 - Teste de igualdade de variância para o modelo representado pela expressão 5

\begin{tabular}{|c|c|c|}
\hline Metodo & Estatística-F & p-valor \\
\hline Bartlett & 37,695 & 0.000 \\
\hline Levene & 3,876 & 0.000 \\
\hline Brown-Forsythe & 3,075 & 0.002 \\
\hline
\end{tabular}

Esta resposta indica uma forte tendência de não se ter uma distribuição homocedasticidade nos resíduos. Objetivando a ponderação dessa implicação, incluí-se uma matriz de White para os termos do cross-section. A Tabela 4 expóe os resultados estatísticos do modelo representado pela expressão 4, considerando a questão da heterocedasticidade.

Tabela 4 - Resultados estatísticos da expressão 4 - Estimador de efeito fixo e matriz de White no cross-section.

\begin{tabular}{|l|c|c|c|}
\hline \multicolumn{1}{|c|}{ VARIÁVEL } & $\boldsymbol{\beta}_{\boldsymbol{k}}$ & Desvio-padráo & p-valor \\
\hline Constante & $-58,64$ & 21,384 & 0,007 \\
\hline $\mathrm{Y}^{\mathrm{al}}$ & 4,344 & 2,229 & 0,054 \\
\hline $\mathrm{Y}^{\mathrm{e}}$ & 6,787 & 3,464 & 0,052 \\
\hline $\mathrm{AB}^{\mathrm{al}}$ & 2,939 & 1,881 & 0,121 \\
\hline $\mathrm{AB}^{\mathrm{e}}$ & 1,651 & 11,68 & 0,887 \\
\hline $\mathrm{CC}^{\mathrm{al}}$ & 1,634 & 0,769 & 0,036 \\
\hline $\mathrm{IN}^{\mathrm{al}}$ & $-0,037$ & 0,034 & 0,285 \\
\hline $\mathrm{DU}^{\mathrm{al}}$ & 0,299 & 0,144 & 0,040 \\
\hline
\end{tabular}

$\mathrm{R}^{2}: 0,7514$

AIC: 2,2174

CSC: 2,6333

Pela estatística $\mathrm{R}^{2}$ e o AIC tem-se, nessa nova formatação, um melhor ajuste no modelo que busca demarcar os condicionantes macroeconômicos do IDEs voltado para a América Latina. Ademias, a estatística de DW não revela a presença de autocorrelação nos resíduos. As variáveis que apresentaram significância estatísticas foram as seguintes: Yal com sinal positivo, quanto maior a economia da região latino-americana maior a entrada de inversóes espanholas; Ye com relação positiva com IDEs, o tamanho da economia da Espanha influencia de maneira direta os fluxos de investimento em direção a América Latina; $\mathrm{CC}^{\text {al }}$ caracterizado com uma correlação positiva com os 
investimentos espanhóis, ou seja, quanto maior a abertura comercial do país, maior a entrada de investimento direto espanhol; por fim, a dummy de privatizações, DUal, com sinal positivo, os anos de privatização influenciaram de forma positiva na explicação do IDEs.

Ressaltam-se dois pontos logrados pelos resultados estatísticos: (1) o nível de atividade interno dos países latino-americano ou da Espanha não foi estatisticamente relevante no processo de atração de investimento direto espanhol; (2) a inflação média dos últimos cinco anos dos países da América Latina, também, não obteve significância estatística na determinação do IDEs. Estas duas respostas acabam por indicar que nem fatores relacionados com a conjuntura econômica do momento, e nem condiçóes associadas com a estabilidade das economias receptoras foram relevantes na internacionalização das empresas espanholas. Esta última resposta pode estar associada ao processo e reestruturação das economias latino-americana, apresentandose como uma nova perspectiva para as economias da região. Com efeito, toda a instabilidade ocorrida nos períodos anteriores acaba obtendo pouca importância.

Além do que, a pouca importância para variáveis conjunturais $\left(\mathrm{AB}^{\mathrm{al}} \mathrm{e}\right.$ $\mathrm{AB}^{\mathrm{e}}$ ) e de estabilidade econômica ( $\left.\mathrm{IN}^{\mathrm{al}}\right)$, tornando relevante fatores ligados a estrutura das economias ( $\mathrm{Y}^{\mathrm{a}}, \mathrm{Y}^{\mathrm{e}}, \mathrm{CC}^{\mathrm{al}}$ ) e ao processo de privatização da América Latina ( $\left.\mathrm{DU}^{\mathrm{a}}\right)$, fato que vai ao encontro de parte da literatura sobre a dinâmica de internacionalização das economia espanhola em direção a América Latina ${ }^{22}$. Este movimento foi impulsionado, basicamente, pelas transformações derivadas do processo de globalização produtiva agregada à internacionalização das economias européias. Assim, no momento de consolidação da União Européia, foi fundamental as empresas espanholas adquirirem força econômica visando a sua sobrevivência. O processo de privatização das estatais dos países latino-americanos criou a janela de oportunidade para investimentos capazes de elevar a de escala produtiva dos grupos espanhóis.

Em resumo, os condicionantes macroeconômicos do IDEs para a América Latina nos anos 1990 foram o tamanho das economias de origem

\footnotetext{
${ }^{22}$ De acordo com esta hipótese, os push factors teriam precedência na explicação do boom de IDEes na América Latina. Ver, por exemplo, Cepal (2002a, 2006), Sánchez Díez (2002), Casilda Béjar e Calderón (2000), Casilda Béjar (2003), Chislett (2003) e Ruesga e Bichara (2004).
} 
(Espanha) e receptoras (a grandeza do mercado interno) e o grau de abertura comercial (bens e serviços) destas. Este movimento teve como pano de fundo a dinâmica das privatizaçóes ocorridas nesta região, além da necessidade de internacionalização da economia espanhola.

Já definidos os determinantes macroeconômicos do investimento direto espanhol na América Latina, coloca-se a questão de como estas inversóes influenciaram a dinâmica interna das regióes receptoras. Em um primeiro momento busca-se uma relação entre o IDEs e a taxa de investimento dos países latino-americanos. As variáveis utilizadas neste exercício são identificadas a seguir:

(A) Taxa de investimento das economias latino-americanas $\left(I^{\text {al }}\right)$ : representa a participação da formação bruta de capital no PIB de cada país da América Latina, em termos percentuais. Este agregado teve como fonte de dados brutos o World Development Indicators 2005, base de dados construída pelo Banco Mundial.

(B) Taxa de crescimento real da renda das economias latino-americanas ( $\left.\mathrm{TY}^{\mathrm{a}}{ }^{\mathrm{l}}\right)$ : esta taxa de crescimento foi construída partindo do agregado em moeda nacional ${ }^{23}$, utilizada em valores percentuais. Espera-se uma relaçáo positiva entre a $\mathrm{I}^{\text {al }}$ e esta variável, uma vez que, a aumento no nível de atividade impulsiona a formação bruta de capital. A fonte de dados brutos da TYal foi o World Development Indicators 2005.

(C) Taxa de inflaçáo dos países latino-americanos $\left(\right.$ INF $\left.^{a l}\right)$ : Diferentemente da variável que especificava o comportamento dos preços no exercício do IDEs, para a determinação do I ${ }^{\text {al }}$ a alternativa foi utilizar-se da taxa de inflaçáo anual. Crê-se que a dinâmica da formaçáo bruta de capital não se expressa da mesma maneira que os fluxos de investimento direto estrangeiros. A sensibilidade da $\mathrm{I}^{\text {al }}$ com relação à estabilidade interna do país é menor, pois, o conjunto de alternativas do investidor nacional é menor. Por fim, a expectativa é de que exista uma relação inversa entre o I ${ }^{\text {al }}$ e a INFal. Novamente, a fonte de dados brutos para este agregado foi o World Development Indicators 2005.

(D) Taxa real de juros dos países da América Latina (TX'): Emprega-se a taxa nominal de juros descontada pelo índice de preço ao consumidor. Sendo que,

\footnotetext{
${ }^{23}$ A opção por trabalhar em moeda nacional, diferente do exercício de determinação do IDEs, foi movida pelo fato de que o I ${ }^{\text {al }}$ é um agregado da economia nacional dos países latino-americanos.
} 
teoricamente, a relação sugerida é inversa entre a $\mathrm{TX}^{\mathrm{al}}$ e a $\mathrm{I}^{\mathrm{al}}$. A fonte de dados brutos para a taxa rela de juros foi o International Financial Statistic Database - FMI.

Ainda utilizou-se do IDEs como condicionante da taxa de investimento dos países latino-americanos. Salienta-se que para este exercício excluí-se o ano de 1993, visto que, há uma troca de moeda na economia brasileira a partir do ano de 1994, causando distorçóes na taxa de juros real desta regiáo. Com efeito, a expressão que se busca delimitar é apresentada a seguir:

$$
I_{i t}^{a l}=\beta_{i 0}+\beta_{1} T Y_{i t}^{a l}+\beta_{2} T X_{i t}^{a l}+\beta_{3} I N F_{i t}^{a l}+\beta_{4} I D E s_{i t}+\varepsilon_{i t}
$$

Não é possível rejeitar a hipótese de presença de heterocedasticidade nos resíduos do modelo estatístico representado pela equação acima (Tabela 5). De mais a mais, tem-se a presença de autocorrelação serial nos termos não observáveis ${ }^{24}$.

Tabela 5 - Teste de igualdade de variância para o modelo representado pela expressáo 5

\begin{tabular}{|l|c|c|c|}
\hline & Metodo & Estatística-F & p-valor \\
\hline Bartlett & 28,393 & 0,001 \\
\hline Levene & 4,8611 & 0.000 \\
\hline Brown-Forsythe & 3,4872 & 0,001 \\
\hline
\end{tabular}

Incluí-se, portanto, um termo auto-regressivo de $1^{\text {a }}$ ordem e uma matriz de White no cross-section. Os resultados dessa nova especificação são apresentados na Tabela 6 .

\footnotetext{
${ }^{24}$ Este tipo de resultado é comum em dados de painel, uma vez que, especifica-se dados de corte, potencial causador da heterocedasticidade, associado à série de tempo, motivando uma probabilidade de autocorrelação residual.
} 
Tabela 6 - Resultados estatísticos da expressão 5 - Estimador de efeito fixo e matriz de White no cross-section.

\begin{tabular}{|l|c|c|c|}
\hline \multicolumn{1}{|c|}{ VARIÁVEL } & $\boldsymbol{\beta}_{\boldsymbol{k}}$ & Desvio-padrão & p-valor \\
\hline Constante & 17,19 & 1,414 & 0,000 \\
\hline TY' & 0,341 & 0,078 & 0,000 \\
\hline TX $^{\text {al }}$ & 6,830 & 3,956 & 0,088 \\
\hline INF $^{\text {al }}$ & 0,001 & 0,001 & 0,329 \\
\hline IDEs & 0,253 & 0,307 & 0,410 \\
\hline AR(1) & 0,639 & 0,121 & 0,000 \\
\hline
\end{tabular}

$\mathrm{R}^{2}: 0,8076$

AIC: 4,3816

CSC: 4,8010

A estrutura estatística indicada na Tabela 5 apresenta o termo autoregressivo estatisticamente significativo e com sinal positivo. Somando-se a isso, tem-se dificuldades em rejeitar a hipótese nula da estatística-t, a um nível de 5\%, associada aos parâmetros da TX ${ }^{\text {al }}$, INFal e IDEs. Por conseqüência, a única variável, além do termo $\mathrm{AR}$, que apresentou relevância estatisticamente na explicação das variações na taxa de investimento foi o nível de atividade ${ }^{25}$. Pode-se imaginar que o IDEs, de alguma forma, estaria influenciando a atividade econômica dos países receptores e, de maneira indireta a ${ }^{\text {al }}$. No entanto, como foi observado anteriormente, não se atingiu robustez estatística para a relação entre IDEs e $\mathrm{AB}^{\mathrm{al}}$, dificultando esta afirmação.

Além de apresentar a influência do IDEs em direção a taxa de investimento dos países da América Latina, pretende-se demarcar como essas inversóes influenciaram as vendas externas das regiōes receptora de inversão. Para isso, faz-se uso das seguintes variáveis:

(A) Exportaçóes de bens e serviços das economias latino-americanas (EX $\left.{ }^{\mathrm{al}}\right)$ : este agregado representa as vendas externas dos países selecionados na amostra trabalhada em valores constantes (US\$) de 2000. A fonte de dados brutos para as EX foi o World Development Indicators 2005.

(B) Importaçóes mundiais de bens e serviços $\left(\mathrm{IM}^{\mathrm{al}}\right)$ : esta variável representa a

${ }^{25}$ Esta conclusão é reforçada no trabalho de Blomstrom, Lipsey e Zejan (1996) para um painel com 101 países. 
demanda mundial por bens e serviços latino-americanos. Não diferente da formatação das EX $^{\text {al }}$ as IM ${ }^{\text {al }}$ encontram-se em US $\$$ constantes de 2000, tal que, a fonte de dados brutas dessa variável também foi o World Development Indicators 2005. Espera-se uma relação positiva entre as $\mathrm{EX}^{\mathrm{al}}$ e a demanda mundial.

(C) Índice da taxa de câmbio real das economias da América Latina $\left(\mathrm{CA}^{\mathrm{al}}\right)$ : a taxa de câmbio real foi obtida ao se multiplicar a taxa de câmbio nominal pela relaçáo preços internacionais e preços internos de cada país. O preço internacional foi caracterizado pelo índice de preço ao atacado da economia estadunidense, por sua vez, para os preços internos utilizou o índice de preço ao consumidor de cada país. Com a taxa de câmbio real obtida, com base fixa igual a 100 no ano de 1994 para todos os países, opera-se, ainda, uma transformação logarítmica. A fonte de dados brutos para estes agregados foram: World Development Indicators 2005 e o International Financial Statistic Database - FMI. Teoricamente a relação entre CA ${ }^{\text {al }} \mathrm{e}$ vendas externas é positiva, ou seja, quanto menor esta taxa menor as vendas externas da região.

(D) Taxa de absorçáo interna dos países da América Latina ( $\left.\mathrm{AB}^{\mathrm{al}}\right)$ : empregou-se este agregado com a mesma especificação do exercício de delimitação das variáveis macroeconômicas que influenciaram o IDEs. Neste caso, não se tem convicção da relação entre $\mathrm{EX}^{\mathrm{al}}$ e o nível de atividade interno da regióes. Ao se atingir uma relaçáo negativa conclui-se que as vendas externas ocorriam em momentos de desaquecimento do mercado interno. Já para a situaçáo inversa, as EXal dinamizam a economia interna da região.

O IDEs também foi aproveitado como balizador das $\mathrm{EX}^{\mathrm{al}}$, sendo que, da mesma maneira do exercício empregado para a $\mathrm{I}^{\text {al }}$, serviu-se dos anos de 1994 até 2003 . Este fato foi provocado, novamente, pela alteração do padrão monetário na economia brasileira, causando distorções no valor da taxa de câmbio real. Segue, portanto, a estrutura a ser estimada:

$$
E X_{i t}^{a l}=\beta_{i 0}+\beta_{1} C A_{i t}^{a l}+\beta_{2} I M_{t}^{a l}+\beta_{3} A B_{i t}^{a l}+\beta_{4} I D E s_{i t}+\varepsilon_{i t}
$$

Dois problemas foram encontrados nas respostas estatísticas da expressão 6 . A estatística DW indica a presença de autocorrelação serial nos resíduos e tem-se dificuldades em não rejeitar a hipótese de heterocedasticidade (Tabela 7). 
Tabela 7 - Teste de igualdade de variância para o modelo representado pela expressão 6

\begin{tabular}{|c|c|c|}
\hline Metodo & Estatística-F & p-valor \\
\hline Bartlett & 28,393 & 0,001 \\
\hline Levene & 4,8611 & 0.000 \\
\hline Brown-Forsythe & 3,4872 & 0,001 \\
\hline
\end{tabular}

Visando solucionar o problema da autocorrelação nos resíduos foi necessário incluir na estrutura da equação 6 dois termos autoregressivos $(\mathrm{AR}(1)$ e $\mathrm{AR}(2))$, indicando a presença de autocorrelação de segunda ordem nos termos não observáveis. Já a ponderação da heterocedasticidade foi obtida da mesma maneira aplicada anteriormente, incluí-se uma matriz de White nos termos do cross-section. O produto estatístico dessa nova caracterização é apresentado na Tabela 8 .

Tabela 8 - Resultados estatísticos da expressáo 6 - Estimador de efeito fixo e matriz de White no cross-section

\begin{tabular}{|l|c|c|c|}
\multicolumn{1}{c|}{ VARIÁVEL } & $\boldsymbol{\beta}_{\boldsymbol{k}}$ & Desvio-padráo & p-valor \\
\hline constante & 4,424 & 1,8699 & 0,020 \\
\hline CA $^{\text {al }}$ & 0,016 & 0,0502 & 0,745 \\
\hline $\mathrm{IM}^{\text {al }}$ & 0,441 & 0,1492 & 0,004 \\
\hline $\mathrm{AB}^{\text {al }}$ & $-0,001$ & 0,0004 & 0,892 \\
\hline $\mathrm{IDEs}$ & 0,001 & 0,0059 & 0,963 \\
\hline $\mathrm{AR}(\mathbf{1})$ & 1,114 & 0,0918 & 0,000 \\
\hline $\mathrm{AR}(2)$ & $-0,386$ & 0,1002 & 0,001 \\
\hline
\end{tabular}

$\mathrm{R}^{2}: 0,9972$

AIC: $-3,7258$

CSC: $-3,2472$

O dois termos autoregressivos são significativos estatisticamente, o primeiro apresenta uma relação positiva comas $\mathrm{EX}^{\mathrm{al}}$ e o segundo o contrário ${ }^{26}$. Ademais, somente as $\mathrm{IM}^{\text {al }}$ caracterizam como estatisticamente relevante na explicação das variaçóes das vendas externas das economias latino-americana. Ou seja, não se obteve uma relação segura entre o IDEs e as EX ${ }^{\text {al }}$.

Já particularizada a relação estatística entre o IDEs, as exportaçóes e a taxa

\footnotetext{
${ }^{26}$ Este comportamento indica um padrão cíclico na dinâmica da serie das EXal .
} 
de investimento das economias latino-americanas, busca-se individualizar a afinidade entre IDE e a produtividade do trabalho. Para tanto, utilizou-se cinco variáveis no modelo econométrico proposto:

(A) Produtividade das economias latino-americanas (PRO): a série deste agregado não se encontra de maneira direta. Neste sentido, para alcançar seu valor, partiu-se da série do PIB em US\$ de 2000 juntamente com a série da populaçáo efetivamente ocupada. A simples divisão do produto pela população ocupada mostra o valor produzido por trabalhador, identificando a produtividade do trabalho na região. As fontes de dados brutos das duas séries formam: World Development Indicators 2005 e a Comisión Económica para América Latina y Caribe (CEPAL).

(B) Taxa de crescimento real da renda das economias latino-americanas (TY'al): as mesmas consideraçóes anteriormente apresentadas para esta variável continuam valendo. Acredita-se em uma relação positiva entre a produtividade e a TYal, uma vez que, a elevaçáo do nível de atividade induz uma melhor ocupação dos fatores de produção.

(C) Grau de abertura dos países da América Latina $\left(\mathrm{CC}^{\mathrm{a}}\right)$ : esta variável, agora empregada no exercício de demarcação da produtividade das economias latinoamericanas, foi produzida da mesma forma anterior. Aguarda-se uma relação positiva entre o $\mathrm{CC}^{\text {al }}$ e a produtividade, pois, uma maior abertura comercial possibilita a importação de equipamentos mais baratos e, também, de produtividade mais elevada.

(D) Investimento estrangeiro direto total (IDT): não diferente do formalizado para a série do IDE, emprega-se o deflator da formação bruta máquinas e equipamentos da economia estadunidense, estabelecendo o IDT em US\$ de 2000. Com respeito à relaçáo desta variável e a $\mathrm{PRO}$ esperasse-se que se torne positiva. Isto é, quanto maior participação do capital estrangeiro nas economias da região latino-americana maior seria seu nível de produtividade, dado que se incorporariam novas tecnologias de regiôes mais avançadas.

Da mesma maneira do exercício implementado para $\mathrm{EX}^{\mathrm{al}}$ e para a $\mathrm{I}^{\mathrm{al}}$, usou-se o IDEs como variável que poderia explicar as PRO dos países já selecionados, onde, os anos em estudo permaneceram entre 1994 e 2003. As observaçóes já apontadas para a relação entre o IDT e a PRO conservam-se para ao caso do IDEs. Ou seja, espera-se uma relação positiva entre a PRO 
e o IDE. Assim, a aproximação a ser estimada é identificada da seguinte forma:

$$
P R O_{t}=\beta_{i 0}+\beta_{1} T Y_{i t}^{a l}+\beta_{2} C C_{i t}^{a l}+\beta_{3} I D T_{i t}+\beta_{4} I D E s_{i t}+\varepsilon_{i t}
$$

Novamente, na formulação econométrica caracterizada anteriormente tem-se problemas de autocorrelação residual e heterocedasticidade (Tabela 7)

Tabela 9 - Teste de igualdade de variância para o modelo representado pela expressão 7

\begin{tabular}{|c|c|c|}
\hline Método & Estatística-F & p-valor \\
\hline Bartlett & 41,926 & 0,000 \\
\hline Levene & 3,912 & 0,000 \\
\hline Brown-Forsythe & 2,274 & 0,019 \\
\hline
\end{tabular}

O problema da variância não constante dos resíduos foi minimizado pela imposição de uma matriz de White no cross-section do modelo. Lembrando que este mesmo procedimento foi implementado nos exercícios anteriores. Já a questão da autocorrelação residual foi solucionada com a aplicação de dois termos AR. Por conseqüência, as novas estatísticas são oferecidas na Tabela 10.

Tabela 10 - Resultados estatísticos da expressão 7 - Estimador de efeito fixo e matriz de White no cross-section.

\begin{tabular}{|l|c|c|c|}
\hline \multicolumn{1}{|c|}{ VARIÁVEL } & $\boldsymbol{\beta}_{\boldsymbol{k}}$ & Desvio-padráo & p-valor \\
\hline Constante & 3,935 & 0,0249 & 0,000 \\
\hline TYal $^{\text {al }}$ & 0,002 & 0,0003 & 0,000 \\
\hline CC & $-0,005$ & 0,0183 & 0,786 \\
\hline IDT & $-0,010$ & 0,0047 & 0,033 \\
\hline IDEs & 0,001 & 0,0010 & 0,301 \\
\hline AR(1) & 1,407 & 0,1426 & 0,000 \\
\hline AR(2) & $-0,559$ & 0,1197 & 0,000 \\
\hline
\end{tabular}

$\mathrm{R}^{2}: 0,9991$

AIC: $-6,2963$

CSC: $-5,8177$

Dois agregados macroeconômicos, no modelo estabelecido, influenciaram a PRO dos países selecionados para este exercício. O primeiro deles teria 
sido o nível de atividade, estruturando-se com sinal já esperado. O outro agregado que se tornou significativo para explicar as variaçóes da PRO das economias da América Latina foi o IDT, mas diferente o imaginado, esta variável apresenta uma relação negativa com a PRO, isto é, a elevação do IDT ajudou a diminuir a PRO da região. Este resultado, adicionado a não significância estatística do IDEs, leva a crer que esta relação entre IDT e a PRO seja espúria, pois a parcela majoritária do investimento direto externo (inclusive o espanhol) na América Latina, para os anos da amostra trabalhada, foi direcionado para o setor de serviços. De forma distinta do observado no setor industrial, existe uma dificuldade em estabelecer, de modo preciso, o comportamento da produtividade do trabalho no setor de serviços. Neste sentido, prefere-se desconsiderar a relação encontrada entre o IDT e a PRO. Salienta-se, ainda, o comportamento dos termos AR, recomendando um comportamento cíclico para os ganhos de produtividade. Assim, pelos motivos já expostos não se obteve uma relação estatística robusta entre o IDEs e a produtividade das economias latino-americanas.

As variáveis macroeconômicas utilizadas no exercício anterior serão as mesmas empregadas no exercício da taxa de desemprego. Por conseqüência, as observações feitas anteriormente continuam valendo. Por outro lado, uma objeção é importante ao se tratar da relação entre a taxa de desemprego e o grau de abertura das economias selecionadas, ou seja, pode-se esperar tanto uma relação positiva quanto uma negativa. Para o primeiro caso crê-se que a inserção das economias latino-americanas no comércio mundial teve um impacto positivo no emprego da regiáo. Já para o segundo caso a abertura comercial gerou um aumento da taxa de desemprego nesta região. Ademais, a variável taxa de desemprego dos países da América Latina (TXD) teve como fonte de dados Comision Económica para América Latina y Caribe (CEPAL), medida em taxa percentual. Desde logo, a relação a ser estimada é indicada pela expressão 8, onde já são aplicas diferenças de comportamento da TXD entre os países da amostra.

$$
T X D_{i t}=\beta_{0 i}+\beta_{1} T Y_{i t}^{a l}+\beta_{2} C C_{i t}^{a l}+\beta_{3} I D T_{i t}+\beta_{4} I D E s_{i t}+\varepsilon_{i t}
$$

Assim como nos outros exercícios, os problemas da autocorrelação 
residual e da heterocedasticidade (Tabela 11) persistiram. Empregou-se o mesmo método de correção anteriormente utilizado.

Tabela 11 - Teste de igualdade de variância para o modelo representado pela expressáo (13)

\begin{tabular}{|l|c|c|}
\hline \multicolumn{1}{|c|}{ Método } & Estatística-F & p-valor \\
\hline Bartlett & 31,6406 & 0,000 \\
\hline Levene & 3,7477 & 0,000 \\
\hline Brown-Forsythe & 2,8894 & 0,003 \\
\hline
\end{tabular}

Já com as dificuldades apresentadas anteriormente superadas, nota-se que as variáveis explicativas que obtiveram relevância estatística na explicaçáo dos movimentos da TXD dos países da América Latina foram a TYal o CC ${ }^{\text {al }}$ e o IDT, todas com sinal negativo (Tabela 12), uma elevaçáo em qualquer uma delas proporciona uma queda na TXD. Semelhante aos outros exercícios, o IDEs não apresentou relação estatística com mais esta variável econômica, neste caso a TXD. Este resultado pode estar associado ao fato de que as inversóes espanholas na região latino-americana voltaram-se, na sua maioria, para o processo de privatização. Por conseqüência, não há uma elevação significativa no nível emprego, pois, não ocorre uma ampliação do estoque de capital das economias e, por decorrência, uma ampliação no emprego.

Tabela 12 - Resultados estatísticos da expressão (11) - Estimador de efeito fixo e matriz de White no cross-section

\begin{tabular}{|l|c|c|c|}
\hline \multicolumn{1}{c|}{ VARIÁVEL } & $\boldsymbol{\beta}_{\boldsymbol{k}}$ & Desvio-padráo & p-valor \\
\hline Constante & 21.101 & 1.9944 & 0,000 \\
\hline TY $^{\text {al }}$ & -0.126 & 0.0316 & 0,000 \\
\hline CC $^{\text {al }}$ & -8.356 & 2.5593 & 0,020 \\
\hline IDT & -1.633 & 0.6404 & 0,013 \\
\hline IDEs & 0.019 & 0.1908 & 0,920 \\
\hline AR(1) & 0.669 & 0.0528 & 0,000 \\
\hline
\end{tabular}

$\mathrm{R}^{2}: 0,9246$

AIC: 3,3750

CSC: 3,7944

Em síntese, as respostas estatísticas dos exercícios implementados nesta seção sugerem que: 
(i) Os principais determinantes dos fluxos de investimentos espanhol em direção a América Latina foram o tamanho das economias da amostra (Espanha e as economias latino-americanas) e as reformas estruturais que levaram a uma ampliação da abertura comercial e ao processo de privatização ocorrido nesta regiáo.

(ii) Este resultado vai ao encontro da parcela da literatura apurada anteriormente, para qual a internacionalização da economia espanhola respondeu a aspectos estruturais vinculados à dinâmica de integração européia. As empresas espanholas vislumbraram no espaço econômico latino-americano criado pelas privatizaçóes uma importante oportunidade de crescimento.

(iii) Por outro lado, o fato de os capitais espanhóis se concentrarem no setor de serviços, usualmente pela aquisição de ativos pré-existentes, parece explicar a ausência de relaçóes estatísticas mais robustas entre as inversóes espanholas e as variáveis macroeconômicas consideradas: investimento, exportaçóes, produtividade e emprego. Mais uma vez, a literatura consultada sugere que tais resultados são esperados neste contexto de predomínio de investimentos em setores não-comercializáveis.

\section{Considerações finais}

Nos marcos da literatura analisada ao longo do presente trabalho, foi possível encontrar evidências de que os investimentos espanhóis que se direcionaram para a América Latina a partir dos anos 1990 foram determinados por uma interação entre os assim-chamados push-factors - no caso, o tamanho da economia espanhola - e os pull-factors (tamanho das economias latinoamericanas, abertura comercial e privatizaçóes). Os resultados o exercício econométrico do item 5 podem ser interpretados da seguinte forma: as privatizações criaram a oportunidade de inversão, que foi incorporada nas estratégias das corporações espanholas que, por sua vez, vinham experimentando estímulos positivos derivados do próprio fortalecimento da economia espanhola nos marcos da integração à União Européia, bem como os limites potenciais ao seu próprio crescimento no espaço europeu. Por outro lado, não foi possível encontrar uma relação estatística robusta entre aqueles investimentos e o desempenho macroeconômico das economias latino-americanas em termos de crescimento da renda, exportaçóes, formação bruta de capital, produtividade e emprego. Tal resultado também encontra respaldo na literatura, na medida em que os investimentos diretos espanhóis 
se concentraram nos setores de bens não-comercializáveis. Os resultados encontrados nos levam a considerar que novas pesquisas são necessárias para aprofundar nossa compreensão sobre a importância dos fluxos de investimentos espanhóis na América Latina. Um desafio em particular seria de estabelecer análises setoriais que permitissem aferir com mais precisão os efeitos microeconômicos do IDE espanhol. 


\section{Referências Bibliográficas}

AIZENMAN, Joshua; NOY, Ilan. FDI and trade: two way linkages? NBER Working Paper, Cambridge-MA: National Bureau of Economic Research, n. 11403, 2005.

ALFARO Laura. Foreign Direct Investment and growth: does the sector matter? Boston: Harvard Business School, 2003. Disponível em: http://www.grips. ac.jp/teacher/oono/hp/docu01/paper14.pdf. Acesso em: 15 ago. 2006.

ARELLANO, Manuel; BOVER, Olympia. La econometria de datos de panel. Investigaciones Econômicas, Madrid, Fundación SEPI, v. 14, n. 1, p. 3-45, 1990.

BALESTRA, Pietro. Introduction to linear models for panel data. In: MATYAS, Laszlo and SEVESTRE, Patrick (Ed.). The econometrics of panel data: handbook of theory and applications. Dordrecht and London: Kluwer Academic Publishers, 1992.

BHAGWATI, Jagdish. The capital myth: the difference between trade in widgets and trade in dollars. Foreign Affairs, n. 77, p. 7-12, 1998.

BLOMSTROM, Magnus; LIPSEY, Robert E.; ZEJAN, Mario. Is fixed investment the key to economic growth? Quarterly Journal of Economics, v. CXI, Issue 1, p. 269-276, Feb. 1996.

CASILDA BÉJAR, Ramón. La década dorada: economía e inversiones españolas en América Latina (1990-2000). Servicio de Publicaciones de la Universidad de Alcalá de Henares, Colección de Economía, 2003.

CASILDA BÉJAR, Ramón.; CALDERÓN, Alvaro. The spanish banks strategies Latin America. Review of Cepal, n. 70, 2000.

CEPAL. Desarrollo productivo en economías abiertas. Santiago de Chile: Comisión Económica para América Latina y Caribe, 2004.

CEPAL. Globalización y desarrollo. Santiago de Chile: Comisión Económica para América Latina y Caribe, 2002a. 
CEPAL. La inversión extranjera en América Latina y el Caribe 2001. Santiago de Chile: Comisión Económica para América Latina y Caribe, 2002b.

CEPAL. La inversión extranjera en América Latina y el Caribe 2005. Santiago de Chile: Comisión Económica para América Latina y Caribe, 2006.

CHISLETT, William. Spanish Direct Investment in Latin America: challenges and opportunities. Madrid-ES: Real Instituto Elcano, 2003.

FELDSTEIN, Martin.; HORIOKA, Charles. Domestic saving and international capital flows. The Economic Journal, v. 90, p. 314-329, 1980.

HANSEN, Henrik; RAND, John. On the causal links between FDI and growth in developing countries. Copenhagen: Institute of Economics, University of Copenhagen Development Economics Research Group (DERG), 2004. Disponível em: http://www.econ.ku.dk/wpa/pink/2004/0430.pdf. Acesso em: 15 ago. 2006.

JOHNSTON, Jack; DINARDO, John. Econometric methods. New York: McGraw-Hill, 1997.

MACHINEA, José Luis; VERA, Cecília. Comercio, inversión directa e políticas productivas. Serie Informes e Estúdios Especiales, Santiago de Chile, Comisión Económica para América Latina y el Caribe, n. 16, 2006.

OECD. Foreign Direct Investment for Development: maximising benefits, minimising costs. Organisation for Economic Co-operation and Development, 2002.

PRASAD, Eswar; ROGOFF, Kenneth; WEI, Shang-Jin.; KOSE, Ayhan M. Effects of financial globalization on developing countries: some empirical evidence. Washington-DC: International Monetary Fund, Sept. 2003.

RODRÍGUEZ, Francisco; RODRIK, Dani. Trade policy and economic growth: a skeptic's guide to the cross-national evidence. NBER Working Paper, Cambridge-MA, National Bureau of Economic Research, n. 7081, 2000.

RODRIK, Dani. Growth strategies. In: AGHION, Phillipe; DURLAUF, Steven (Ed.). Handbook of economic growth. Cambridge-MA: Elsevier, 2005. 
RODRIK, Dani. Who needs capital account convertibility? Harvard University, Feb. 1998. Disponível em: http://ksghome.harvard.edu/ - .drodrik.academic. ksg/papers.html. Acesso em: 8 jan. 2005.

RUESGA, Santos Miguel; BICHARA, Julimar Silva. Direct Spanish foreign investment in Latin America: determinants and company strategy. Canadian Journal of Development Studies, XXV, n. 2, p. 321-334, 2004.

SÁNCHEZ DÍEZ, Ángeles. La internacionalización de la economía española hacia América Latina. Burgos-ES: Universidad de Burgos, 2002.

UNCTAD. Trade and Development Report, 2004. Geneve: United Nations Conference on Trade and Development, 2004.

UNCTAD. Trade and Development Report, 2005. Geneve: United Nations Conference on Trade and Development, 2005b.

UNCTAD. World Investment Report, 2005. Geneve: United Nations Conference on Trade and Development, 2005a.

WINTERS, Alan. Trade liberalization and economic performance: an overview. The Economic Journal, v. 114, p. 4-21, Feb. 2004.

WOOLDRIDGE, Jeffrey M. Econometric analysis of cross section and panel data. Cambridge, Massachusetts: The MIT Press, 2001.

WORLD BANK. Economic growth in the 1990s: learning from a decade of reform. Washington, DC: World Bank, 2005.

WORLD BANK. The east asian miracle: economic growth and public policy. New York: Oxford University Press, 1993. 